\title{
Wii Fit for Balance Training in Elderly: A Systematic Review
}

\author{
Ayesha Afridi ${ }^{1}$, Farooq Azam Rathore ${ }^{2}$ and Shaikh Nabi Bukhsh Nazir ${ }^{3}$ \\ ${ }^{1}$ Faculty of Rehabilitation \& Allied Health Sciences, Riphah International University, Islamabad, Pakistan \\ ${ }^{2}$ Department of Rehabilitation Medicine, PNS Shifa Hospital, Karachi, Pakistan \\ ${ }^{3}$ Department of Physiotherapy, IPMR, Dow University of Health Sciences, Karachi, Pakistan
}

\begin{abstract}
Falls due to poor balance are common in elderly people and can cause fractures, head injury, soft tissue trauma; and may even result in death from these complications. Balance training is one of the strategies used to prevent falls among the elderly population. Wii Fit is a new technological approach of balance training in the community dwelling elderly. The primary aim of this systematic review is to study the effectiveness of Wii Fit as a balance-training tool in older adults using various balance and fall risk assessment scales as outcome measures. Using selected keywords in English only, online literature search was conducted from 2009 to 2019. The initial search resulted in 312 articles. After screening, 14 full text articles were included for the final review and qualitative analysis. There is evidence that Wii Fit plus is a useful, cost-effective, userfriendly, less time consuming, home-based approach for reducing the risk of fall and improving the balance and physical performance in older adults. There are few or no adverse events of using Wii Fit. The commonly used outcome measures were 8 foot up and go test, activities-specific balance confidence scale, Berg balance scale, falls efficacy scale, postural sway, times up and go test and static and dynamic balance assessment tool.
\end{abstract}

Key Words: Postural balance, Rehabilitation, Video games, Virtual reality, Evidence-based medicine, Technology.

How to cite this article: Afridi A, Rathore FA, Nazir SNB. Wii Fit for Balance Training in Elderly: A Systematic Review. J Coll Physicians Surg Pak 2021; 31(05):559-566.

\section{INTRODUCTION}

It is expected that by 2050 , the population of elders (Age $>60$ years) will be more than two billion and most of them will be residing in Asia. ${ }^{1}$ Elderly populations, who perform regular exercise of moderate intensity throughout the week, are more active and healthier than those with a sedentary lifestyle. ${ }^{2}$ Balance is defined as the ability of the physiological systems to control bodily alignment in an upright position during static and dynamic postures and to maintain the centre of mass within the base of support. ${ }^{3}$ Aging results in a decreased quality and quantity of muscle fibers with low strength and power to bear weight or to maintain the body upright, decrease endurance and capacity to efficiently work in coordination with the nervous system. ${ }^{4}$ Elderly people have reduced potential and stamina for exercise, leading to a sedentary lifestyle that may result in a vicious cycle of muscle weakness and wasting.

Correspondence to: Dr. Farooq Azam Rathore, Department of Rehabilitation Medicine, PNS Shifa Hospital, Karachi, Pakistan

E-mail:farooqrathore@gmail.com

Received: May 10, 2020; Revised: August 04, 2020;

Accepted: March 22, 2021

DOI: https://doi.org/10.29271/jcpsp.2021.05.559
This further contributes to poor stamina and mobility. ${ }^{2,5}$ Elderly populations have a higher risk of balance impairment, disturbed gait pattern and poor coordination of body movements, which may lead to falls or fear of fall. ${ }^{1,6}$ There are many consequences of impaired balance, which can adversely affect physical functioning. Falls related to impaired balance are considered more fatal than any other consequence; because falls are the main source of morbidity among the geriatric population. ${ }^{7}$ The frequency of falls increases with age and an estimated one-third of the older adults had at least one fall over the year. ${ }^{9}$ Most falls accidents happen when walking. Falls may result in further problems like fear of more falls, psychological disturbances, isolation, activity limitations, and increased financial burden for the family. ${ }^{8,9} \mathrm{Hip}$ fractures as a result of fall can further limit the participation of community dwelling older adults. These fractures may prove to be fatal or even if non-fatal, may result in prolonged hospitalisation of individuals. ${ }^{10,11}$

Management of falls and the resulting morbidities require substantial involvement of healthcare professionals. It can result in extra burden for the rehabilitation professionals and prolonged therapysessions, whichare usually notfollowed up by community-dwelling older adults. ${ }^{12,13}$

Different approaches to manage balance impairment and postural instability in community dwelling older adults have been recommended. These include specially designed exercise 
programmes for targeted muscle's strength, endurance, stretching, ${ }^{14}$ sensory feedback training, vestibular rehabilitation with reaction time training, cognitive exercises, ${ }^{15}$ frequent proprioceptor's stimulation around muscles and joints, ${ }^{16}$ taichi, ${ }^{17}$ environmental modification with proper ergonomics, and circuittraining. ${ }^{18}$

These interventions improve balance, increase the quality of life (QOL), and reduce the risk of falls. ${ }^{19,20}$

The virtual reality-based rehabilitation is a recent technology with a sensory feedback approach that targets and challenges the vision, hearing, vestibular system and proprioceptors at a time in three-dimensional landscapes. ${ }^{21}$ Different gaming consoles are available in the market for entertainment and clinical use. Wii Fit was launched as software, specifically for balance rehabilitation with strengthening and endurance of core muscles. It has different yoga poses and generalised fitness games. Compared to other virtual reality exer-gaming tools, Wii Fit is inexpensive and with easy instructions for use at home. Each game consists of different levels, which can be unlocked when previous levels are completed. The higher levels require more precise and accurate muscle activity, motor control, and good reaction time.

Wii Fit is an innovative and interactive device that challenges postural control by the complexity of the task and the environment. It is a reliable and valid tool for assessment of standing balance in the elderly. ${ }^{22,23}$

The aim of this systematic review was to assess the usefulness of Wii Fit as a balance-training tool in the elderly population. The results may be of clinical importance for the future development of clinical guidelines regarding balance dysfunction in community-dwelling olderpeople.

\section{METHODOLOGY}

The systematic review is reported in accordance with the preferred reporting itemsforsystematic reviewsand meta-analysis (PRISMA) guidelines. ${ }^{24}$ This review title was prospectively registered on JBI website (http://joannabriggs.org/research/ registered_titles.aspx).

The eligibility criterion for this systematic review was based on the PICOS criteria.

Participants were healthy older adults ( $>60$ years), who had Wii Fit training alone or Wii Fit training along with exercise therapy. Treatment time lasted for at least of three weeks' duration. Comparison was made with traditional balance exercises along with/or without Wii Fit training or no intervention at all. Outcome was balance improvement and fall risk/prevention assessment using various scales and tools. Only randomised controlled trials (RCTs) were included.

Two authors independently searched six electronic databases. These included five global (Web of Science, Google Scholar, Medline, Literature Latino-Americana e do Caribe em Ciências da Saúde (LILACS) and Physiotherapy Evidence Database) and the local Pakistani database PakMedinet (http://www.pak medinet.com/). We limited the search to studies published between 2009 and 2019 only. The time limit was set because Wii Fit Plus was officially launched in $2009 .{ }^{25}$ Keywords used for the literature search included: Wii Fit, elderly, aged, geriatrics, virtual reality, postural balance, virtual reality, geriatrics, community-dwelling older adults, elderly population, frail adults, virtual reality, Wii Fit plus, exergaming, gaming technology postural balance, postural instability, fall, clinical trial, and randomised controlled trial using a combination of Boolean operators. The reference list of the selected articles was explored for additional studies. The search was restricted to Englishonly.

After literature search, studies were screened and selected according to the predefined PICOS format. The level of evidence for each study was graded by using Oxford Centre for Evidencebased medicine guidelines to evaluate the strength of the included RCTs. ${ }^{26}$

Studies were excluded, if the age of the participants was less than 60 years or they had other health conditions like neurological disorders, fractures, amputations, cognitive impairments or were unable to stand and walk for short distances. Studies in non-English languages, abstracts only, non-RCTs, and primary intervention other than Wii Fit training were also excluded. The PRISMA flow chart of the literature search is presented in Figure $1 .^{24}$

There were two primary outcomes. One was to measure improvement in balance by 8 -ft up and go, activities-specific balance confidence scale (ABCS), Berg balance scale (BBS), Tinetti (Static and Dynamic), neurocom sensory organization test, limits of stability (LOS), timed up and go test (TUG), Romberg test, the centre of gravity/position (COG/P), postural sway, functional reach test (FRT). Second was to assess the fall risk/prevention: measured by Tinetti's falls efficacy scale, unipedal test with eye opened and closed, and physiologic profile assessment scale.

Secondary outcomes were to document the commonly used balance assessment tools in measuring outcomes of balance training, adverse events related to the use of Wii Fit for balance training, and improvement in the health-related quality of life (HRQOL)

\section{RESULTS}

The initial search resulted in 312 articles. Titles were screened and duplicates were excluded. The remaining 170 articles were assessed for eligibility; and further 106 were excluded, since they did not meet the pre-defined PICOS criteria. Fourteen randomised controlled trials, involving 678 participants, were included in the final qualitative review. It was not possible to comment on the gender distribution as two studies did not mention it. ${ }^{27-29}$ Table I mentions the interventions, characteristics, study duration, outcomes, and strength of evidence for each study. 


\begin{tabular}{|c|c|c|c|c|c|c|}
\hline$\overline{\mathrm{g}}$ & $\stackrel{2}{\rightleftharpoons}$ & $\stackrel{2}{\rightleftharpoons}$ & $\stackrel{?}{\rightleftharpoons}$ & $\stackrel{2}{\rightleftharpoons}$ & $\stackrel{\circ}{\rightleftharpoons}$ & $\stackrel{\circ}{\rightleftharpoons}$ \\
\hline 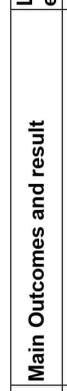 & 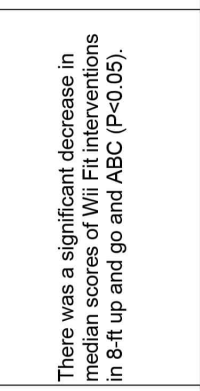 & 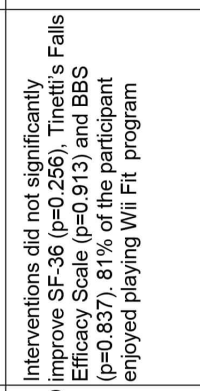 & 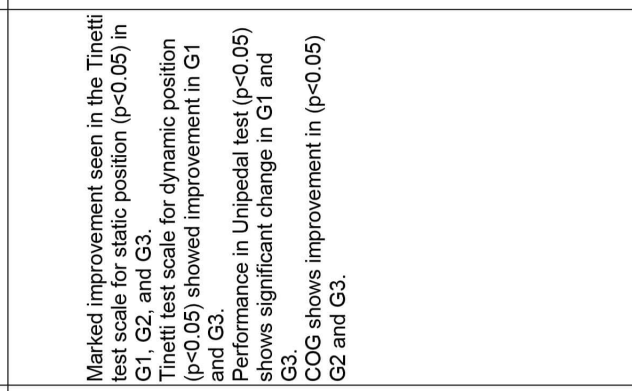 & 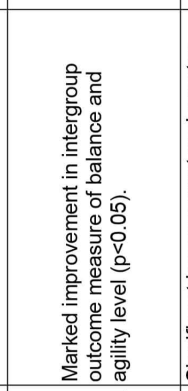 & 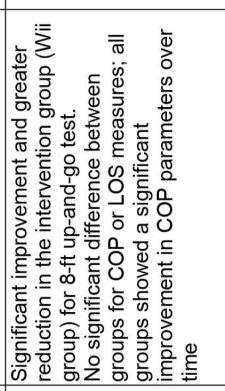 & 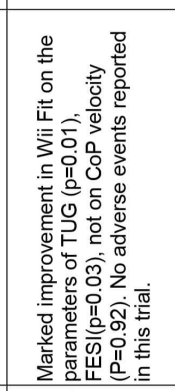 \\
\hline & 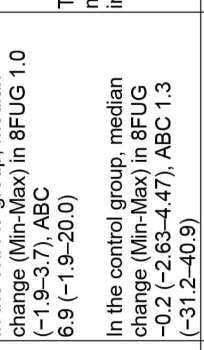 & 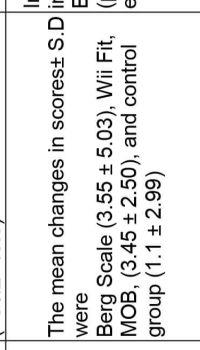 & 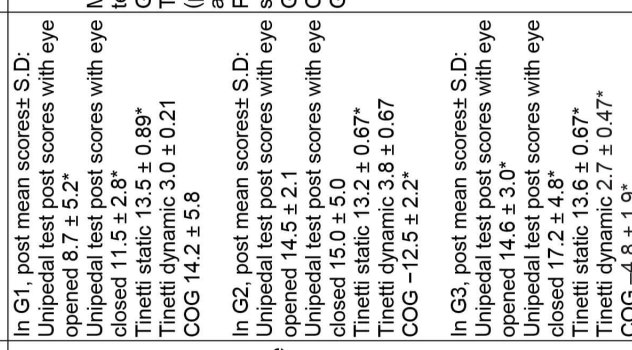 & 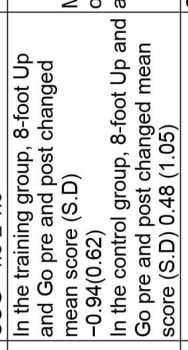 & 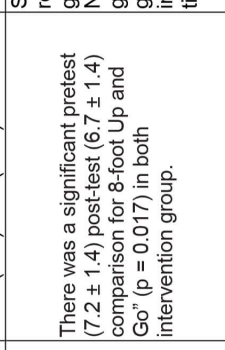 & 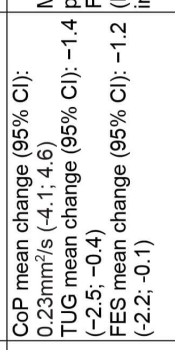 \\
\hline 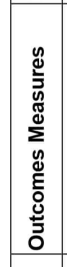 & 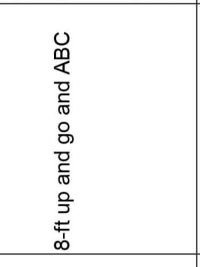 & 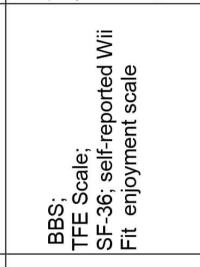 & 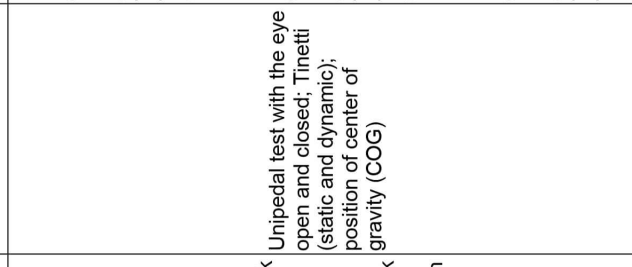 & 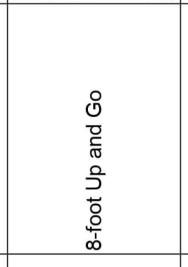 & 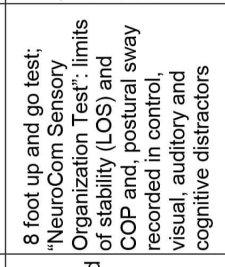 & 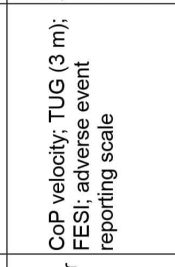 \\
\hline 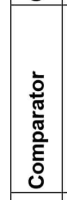 & 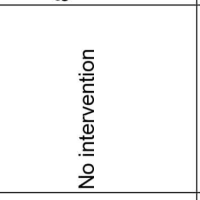 & 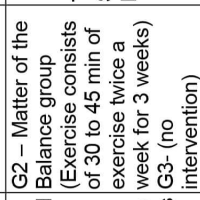 & 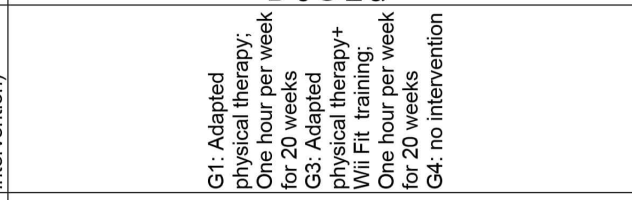 & 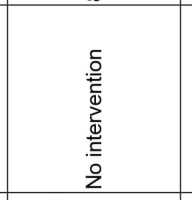 & 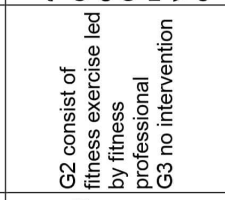 & 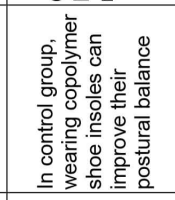 \\
\hline & 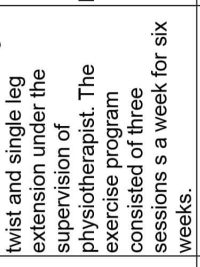 & 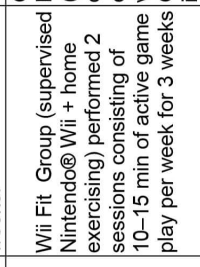 & 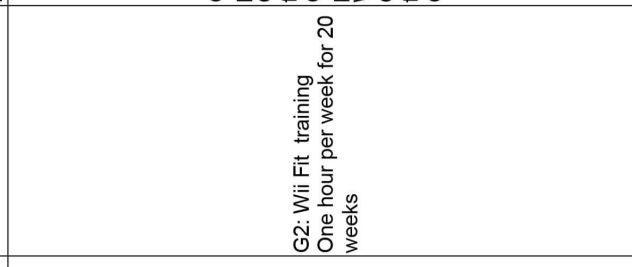 & 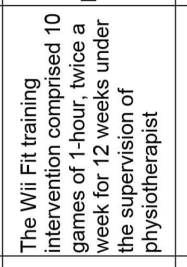 & 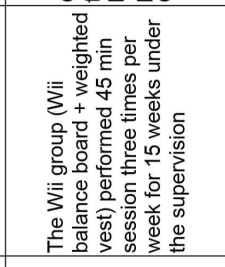 & 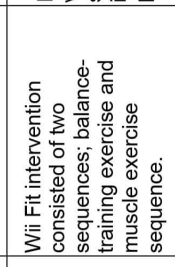 \\
\hline & g & ๗ & $\stackrel{8}{\infty}$ & $\approx$ & $\widehat{\infty}$ & 冓 \\
\hline 告 & 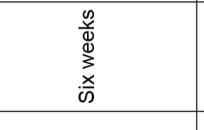 & 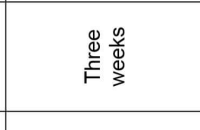 & 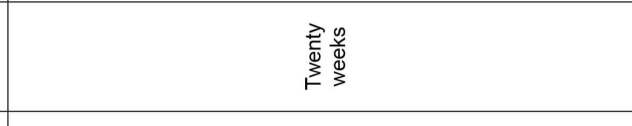 & 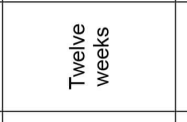 & 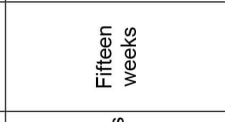 & 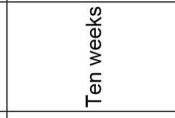 \\
\hline & 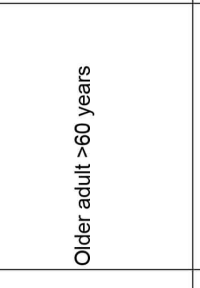 & 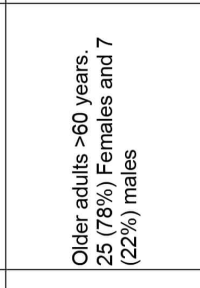 & 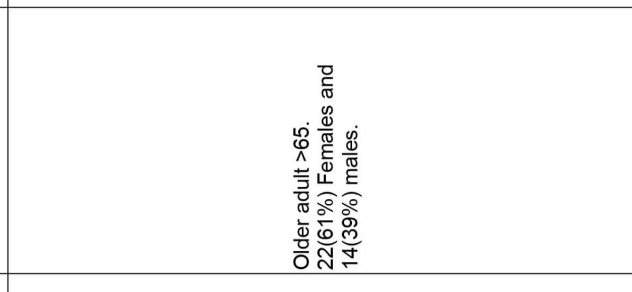 & 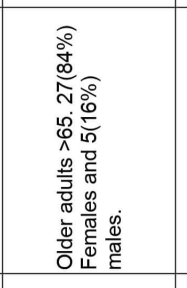 & 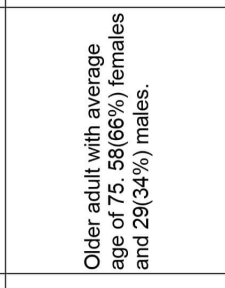 & 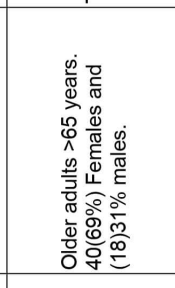 \\
\hline 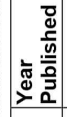 & స̃ & 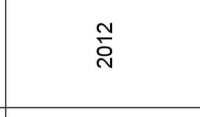 & $\stackrel{N}{N}$ & 亏ั & 亏̃ & $\stackrel{\text { mo }}{\mathfrak{N}^{\circ}}$ \\
\hline $\begin{array}{l}\text { 亳 } \\
\text { 妾 }\end{array}$ & 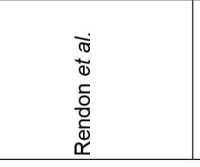 & 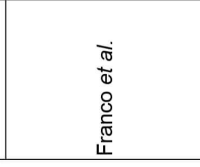 & 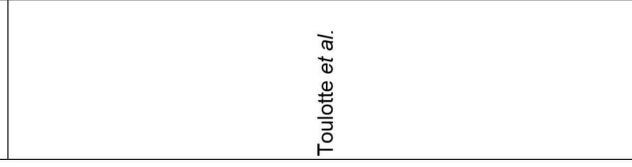 & 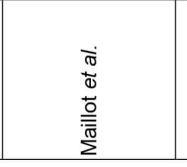 & 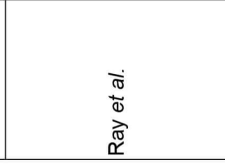 & 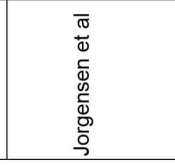 \\
\hline
\end{tabular}




\begin{tabular}{|c|c|c|c|}
\hline 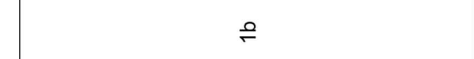 & $\stackrel{?}{\circ}$ & $\stackrel{2}{\circ}$ & $\stackrel{2}{\circ}$ \\
\hline 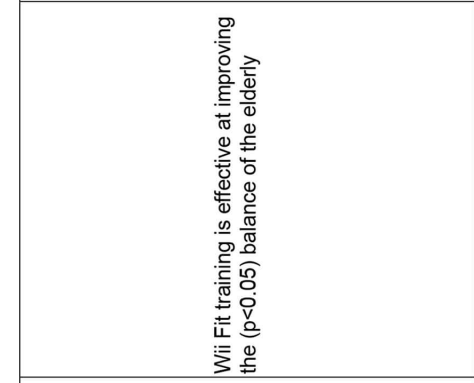 & 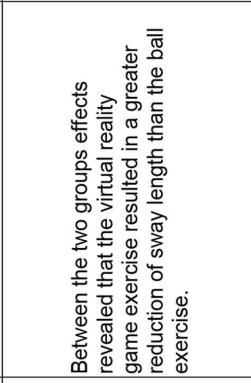 & 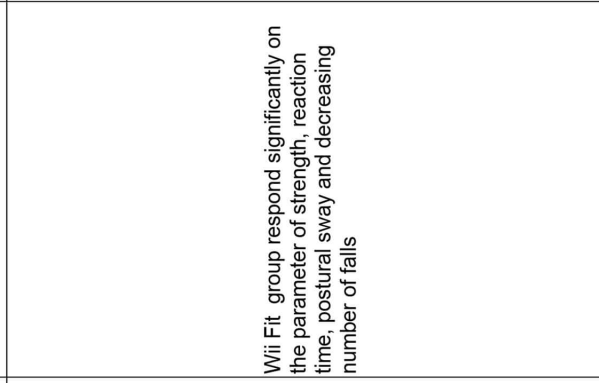 & 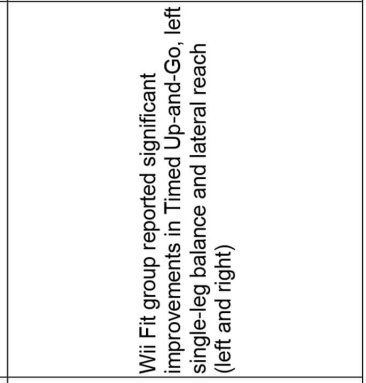 \\
\hline 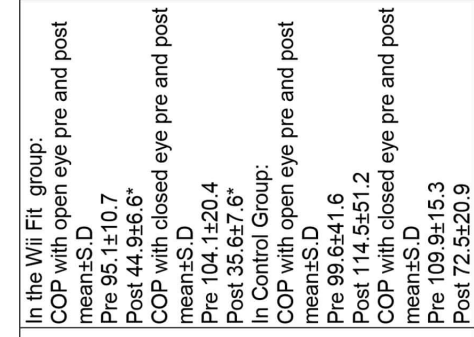 & 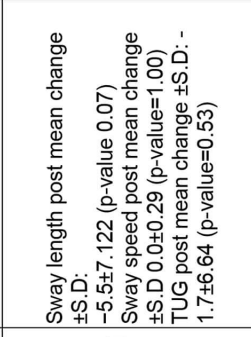 & 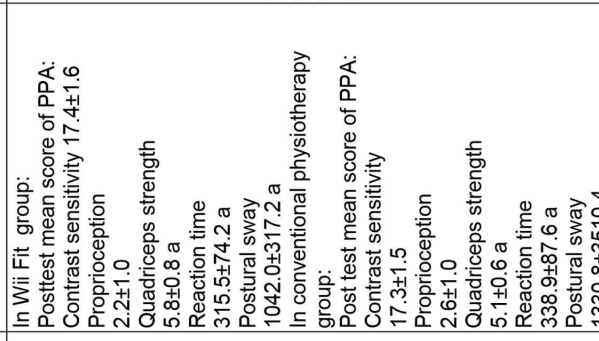 & 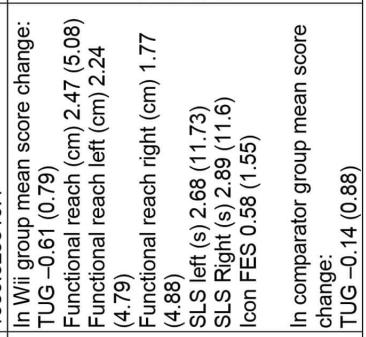 \\
\hline 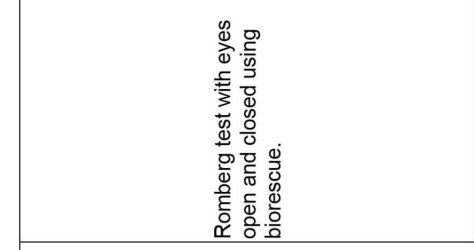 & 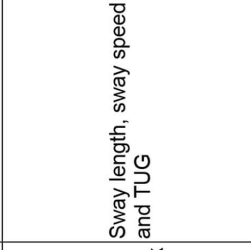 & 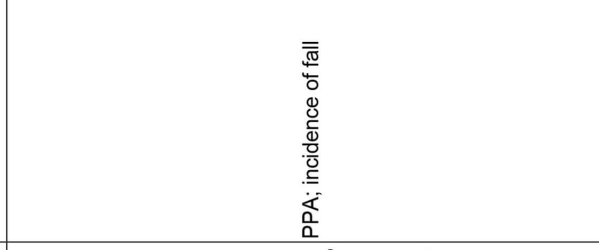 & 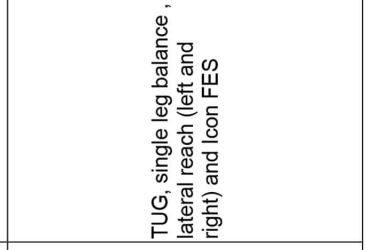 \\
\hline 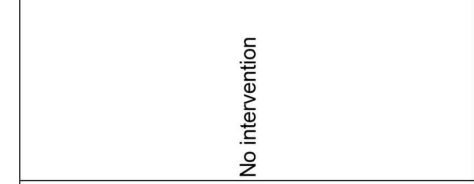 & 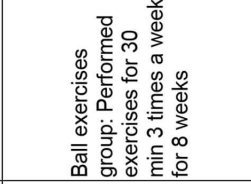 & 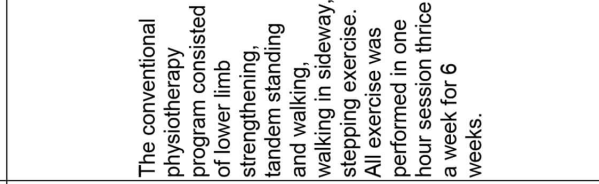 & 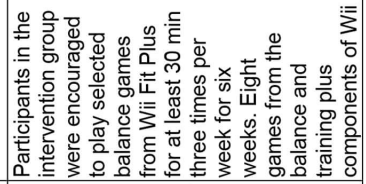 \\
\hline 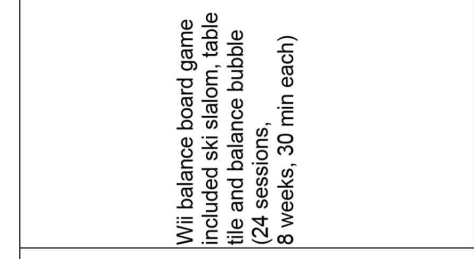 & 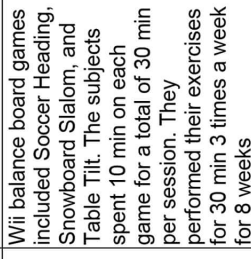 & 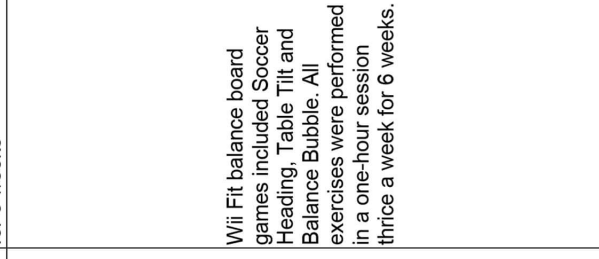 & 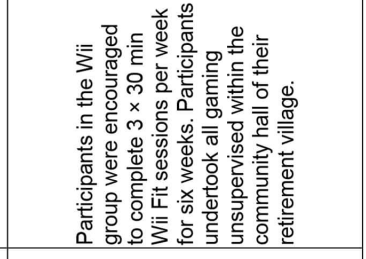 \\
\hline ల & $\stackrel{N}{ }$ & 8 & $\bar{F}$ \\
\hline 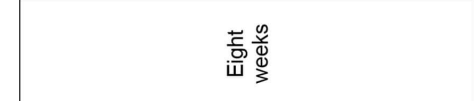 & 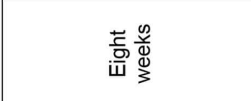 & 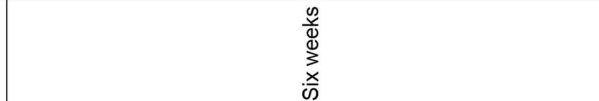 & $\begin{array}{l}\frac{g}{00} \\
\frac{0}{0}\end{array}$ \\
\hline 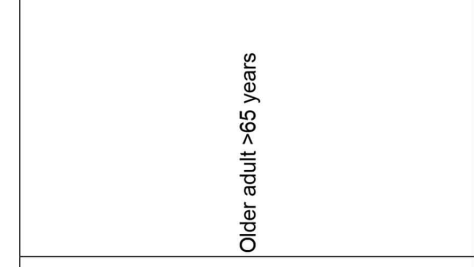 & 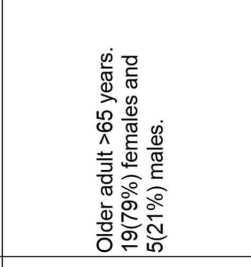 & 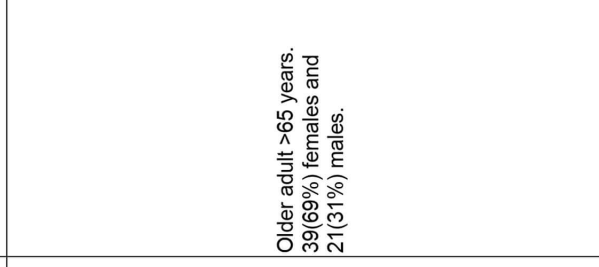 & 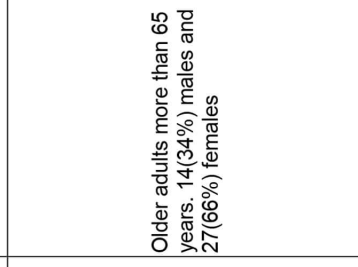 \\
\hline$\stackrel{\stackrel{ \pm}{\sim}}{\sim}$ & $\stackrel{\text { Lे }}{\stackrel{2}{*}}$ & $\stackrel{\mathscr{N}}{\sim}$ & $\stackrel{\text { ñ }}{\sim}$ \\
\hline $\begin{array}{l}\text { d़ } \\
\text { o. } \\
\text { of }\end{array}$ & 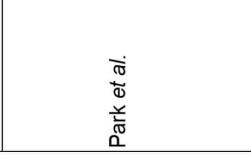 & 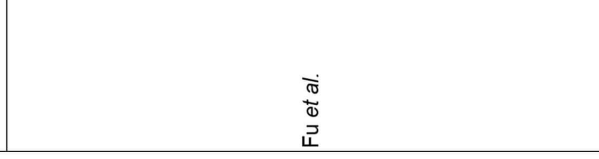 & 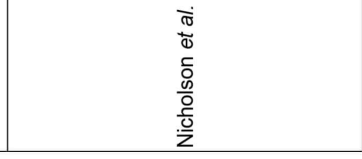 \\
\hline
\end{tabular}


When Wii Fit training compared with no intervention, there was a significant difference $(p>0.05)$ between the post-treatment score of the control and treatment groups in improving the static and dynamic balance in the Wii Fit group as assessed by ABCS, Romberg test and 8 foot up and go test. While these studies documented the only statistically significant difference in the Wii Fit training group, it does not provide insight regarding the extent of improvement in clinical outcomes of the control group. ${ }^{27-29}$

One study reported that there was no significant difference ( $p>0.05$ ) on the BBS, TFE and health-related quality of life, using SF-36 outcome scores when comparing Wii Fit supervised training with the matter of balance group exercise. Compared with ball exercises, there were statistically significant differences in Wii Fit assessed on the parameters of sway length and sway speed. ${ }^{3-30}$

One study of 58 older adults (Wii Fit group and control group wearing copolymer shoe insoles for 10 weeks) focused on adverse events along with other parameters of COP, TUG and FESI. No adverse events were reported in this trial. ${ }^{31}$ Apart from reducing the risk of fall, Wii Fit also improved the balance, physical performance and lower limb strength. Limitations included female's preponderance and recruiting older adults with ideal functioning of musculoskeletal function and postural balance.

One study reported results of Wii Fit training combined with adapted physical therapy in a sample of 36 participants. They assessed various positions of static and dynamic balance using Tinetti test scale, unipedal test, and COG. Wii Fit training along with adapted physical therapy group was superior to other groups in all study parameters. ${ }^{32}$

One study demonstrated significant improvement $(p<0.05)$ in lower limb strength, reaction time, postural sway and decreasing number of falls in the Wii Fit training group. Limitations of the study were a modest sample size and difficult level of exercise for frail adults. ${ }^{33}$

Three studies compared Wii Fit exercises with the control group (consisting of fall prevention education and conventional program) for 6-8 weeks. ${ }^{34-36}$ Outcome measures used included TUG, single leg balance, lateral reach (left and right), Icon FE, BBS, FES and FRT. The results of all three trials showed significant $(P>0.05)$ improvement in physical parameters, such as balance control, reaction time and muscle strength for the Wii Fit groups. However, one study reported exacerbation of back pain in two participants. ${ }^{36}$

Two studies reported the results of RCTs of five weeks duration in which weekly sessions of Wii Fit exercises were compared to the control group. ${ }^{37,38}$ The control group was asked to monitor their daily activities categorized into light, medium and heavy. Static and dynamic balance improved significantly $(p>0.05)$ in the experimental group. ${ }^{37}$ Limitations of these studies included a modest sample size and unclear assessment of the home practice of the interventions.

A sample size of 87 healthy older people was reported, with three arm groups: G1 (experimental group) performed Wii balance board exercises with weighted vest; Group 2 received fitness exercise led by fitness professional; Group 3 did not receive any intervention. The outcome measures used were 8 foot up and go test, NeuroCom Sensory Organization Test, limits of stability, LOS, COP and postural sway. The Wii Fit group and Fitness group showed significant improvement on 8-ft up-and-go test in pre and post time of assessment, but Wii fit group had greater mean difference than the Fitness group. ${ }^{10} \mathrm{~A}$ modest sample size, majority of females, lack of information about the dropout rate and no description of random allocation are the drawbacks of the study.

The Template for Intervention Description and Replication (TIDieR) checklist is an extension of consort 2010 and was published in 2014. This checklist and guideline were developed to help improve completeness in the reporting of interventions in research studies. None of the studies in this review published after 2014 reported and followed the TIDieR checklist. ${ }^{3,33-39}$

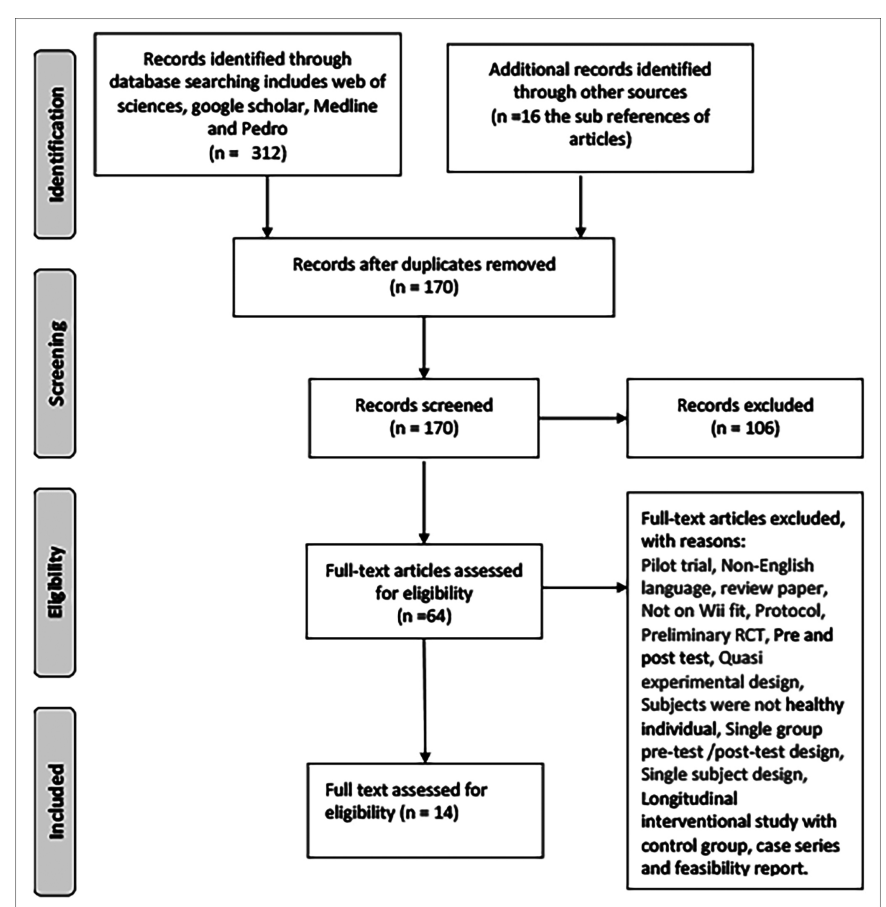

Figure 1: PRISMA flow diagram for literature search.

\section{DISCUSSION}

This systematic review provides evidence that Wii Fit is a useful tool for balance training in the elderly population. There has been a growing interest in using commercial video games rehabilitation in a range of conditions, including stroke, cerebral palsy, Parkinson's disease, balance training, weight loss, and aging. ${ }^{40}$ The Wii Fit system is cost-effective 
and one of the top-selling video console games of all time. ${ }^{41}$ Wii Fit designed to improve postural control in static and dynamic position. The reported benefits of engaging older adults in Wii Fit exergaming include improved range of motion, feelings of social connectedness in their peer groups $^{42}$ and enhanced quality of life. ${ }^{30}$

Wii Fit plus is considered a form of exer-gaming and provides real time visual biofeedback to the player. It consists of Wii console and a balance board connected by Bluetooth. ${ }^{9,43}$ The sensors detect the body position and motion in space. The participant stands over the balance board to play the games, while moving the body in anterior, posterior, left and right sway and maintaining the centre of pressure within the base of support. The game is played with an on screen avatar called Mii. The Mii character reflects the speed, direction and acceleration of movements performed by the participants in three dimensions. It provides a visual feedback of the body movements, which aids the participant to perfectly execute the exercise. Each user can have a separate Mii with their own names and many participants can play the games, simultaneously. Their personal data and playing record were saved and represented visually as graph charts. ${ }^{27,44}$ Assessment of balance improvement noticed in outcome tools needs adequate knowledge of clinometric properties. These properties are potentially overlooked or not properly reported in clinical practice. ${ }^{45,46}$ Minimal detectable change and coefficient of variation percent for tools commonly used to assess balance is required while using the Wii Fit. Thus, it may provide the basis to detect the real change above measurement error in upgrading the everyday clinical practice.

POEM (Patient-oriented evidence that matters) is a useful strategy to focus on upgrading the practice. Wii Fit helps in the prevention of falls by engaging elderly people living in the community and improving their balance ability in the short term but there is only one study portraying the effects of follow up at one year. ${ }^{33}$ There is a need for research to document the long-term outcomes of balance training in the elderly using Wii Fit.

Blinding of participants in an intervention, like Wii Fit, is not possible since every participant can accurately guess whether he/she is in the Wii Fit or the control group. Some studies report that the assessment of balance impairment with the Wii Fit balance board is not as accurate as the traditional balance assessment tools, although it can significantly improve the balance and postural instability in the elderly. ${ }^{47,48}$

Randomised controlled trials that adhere to the highest standards for external and internal validity are important to make the best decisions for patients. Thus, it is necessary to rule out confounders and sources of and bias. Factors such as blinding, allocation concealment and randomisation are important in minimising bias in clinical trials, but even some of the best-designed trials in rehabilitation seem to have some risk of bias. ${ }^{49}$ For example, randomisation is a method based on the chance of allocating the subject into a treatment group that cannot be predicted easily. Few studies were at low bias, according to the risk of the bias assessment tool. $27,28,30,32-33,36$

In a randomised controlled trial, allocation concealment is a useful strategy to hide the method for allocating a participant into a treatment group so that this knowledge cannot be used. Adequate concealment of the assignment serves to prevent participants in the study from selecting treatment assignments. ${ }^{28,30,33,34}$ QoL consists of physical, psychological, and mental health. There is evidence that QoL in the elderly is improved by engaging in physical activity and exercise. In elderly population. ${ }^{30,50}$ These gains in QoL are more pronounced when the Wii Fit activities are performed in groups. ${ }^{51}$

The use of Wii Fit for the elderly is generally safe. Studies reported very few or no adverse events. One study in this review reported adverse effects like back pain, which lead to the patients to drop out from the study. However, this did not require medical attention. ${ }^{48,51}$ Another study reported that one person dropped out from the trial reporting that it was physically too difficult to continue. Wii Fit balance training program can be safely followed at home without the formal supervision of a healthcare professional. ${ }^{36}$ This systematic review favours using Wii Fit as a balance-training tool in the elderly. Based on strength-of-recommendation taxonomy, the evidence would be graded as level A. ${ }^{52}$

The limitations of the review were that it included only RCTs on the use of Wii Fit for balance training published in the English language. This might have missed research published on this topic in languages other than English.

\section{CONCLUSION}

We conclude that in healthy older adults without any cognitive or neurological diseases, Wii Fit is an effective virtual reality approach for balance training. This intervention requires less time per session compared to traditional physical therapy treatment. Moreover, it is user-friendly, engaging, cost-effective and can be delivered at home without the need for supervision by a trained rehabilitation professional. Given the growing popularity of the technological approach as Wii Fit intervention, it would be important for the rehabilitation field to replicate these findings as high quality randomised clinical trials with large sample size and equal distribution of males and females.

\section{CONFLICT OF INTEREST:}

The authors declared no conflict of interest.

\section{AUTHORS' CONTRIBUTION:}

AF: Gave the idea, performed the literature review, wrote the first draft, gave approval of the final version and agreed 
to be accountable for all parts of the work.

FAR: Interpreted the results, revised the manuscript critically and gave approval of the final version and agreed to be accountable for all parts of the work.

SNBN: Did the literature search, analysed and interpreted the results, revised the manuscript critically and gave approval of the final version and agreed to be accountable for all parts of the work.

\section{REFERENCES}

1. Afridi A, Maqbool S, Malik AN. Relationship between fear, fall \& balance in community dwelling older adults. Pak J Neurol Sci 2015; 10(2):5-8.

2. Singh DKA, Rajaratnam B, Palaniswamy V, Raman V, Bong P, Pearson $H$. Effects of balance-focused interactive games compared to therapeutic balance classes for older women. Climacteric 2012; 16(1):141-6. doi.org/10.3109/13697137. 2012.664832.

3. Park EC, Kim SG, Lee CW. The effects of virtual reality game exercise on balance and gait of the elderly. J Phys Ther Sci 2015; 27(4):1157-9. doi.org/10.1589/jpts.27.1157.

4. Maixnerová E, Svoboda Z, Xaverová Z, Dupalová D, Lehnert M. The effect of balance therapy on postural stability in a group of seniors using active video games (Nintendo wii). J Phys Educ Sport 2017; 17(2):735. DOI:10.7752/jpes.2017.02111.

5. Goble DJ, Cone BL, Fling BW. Using the Wii Fit as a tool for balance assessment and neurorehabilitation: the first half decade of "Wii-search." J Neuroeng Rehabil 2014; 11(1):12. doi: 10.1186/1743-0003-11-12.

6. Kumar A, Carpenter H, Morris R, lliffe S, Kendrick D. Which factors are associated with fear of falling in community-dwelling older people? Age Ageing 2014; 43(1):76-84. http://doi.org/10.1093/ageing/aft154.

7. King MB, Tinetti ME. Falls in community-dwelling older persons. J Am Geriatr Soc 1995; 43(10):1146-54. doi.org/10.1111/ j.1532-5415.1995.tb07017.x.

8. Lee A, Biggan JR, Taylor W, Ray C. The effects of a Nintendo Wii exercise intervention on gait in older adults. Act Adapt Aging 2014; 38(1):53-69. http://doi.org/10.1080/01924 788.2013. 878874.

9. Pluchino A, Lee SY, Asfour S, Roos BA, Signorile JF. Pilot Study Comparing Changes in Postural Control After Training Using a Video Game Balance Board Program and 2 Standard Activity-Based Balance Intervention Programs. Arch Phys Med Rehabil 2012; 93(7):1138-46. http://doi.org/10.1016/ j.apmr.2012. 01.023.

10. Ray C, Melton F, Ramirez R, Keller D. The effects of a 15-week exercise intervention on fitness and postural control in older adults. Act Adapt Aging 2012; 36(3):227-41. http://doi.org/ 10.1080/01924788.2012.696236.

11. Benzinger P, Rapp K, König H, Bleibler F, Globas C, Beyersmann J, et al. Risk of osteoporotic fractures following stroke in older persons. Osteoporos In 2015; 26(4):1341-9. http:// doi.org/10.1007/s00198-014-3005-x.

12. Singh DK, Rajaratnam BS, Palaniswamy $V$, Pearson $H$, Raman VP, Bong PS. Participating in a virtual reality balance exercise program can reduce risk and fear of falls. Maturitas 2012; 73(3):239-43. http:// doi.org/10.1016/j.maturitas.2012.07. 011.

13. Baldan A, Alouche S, Araujo I, Freitas S. Effect of light touch on postural sway in individuals with balance problems: A system- atic review. Gait posture 2014; 40(1):1-10. http:// doi.org/10.1016/j.gaitpost.2013.12.028.

14. Markovic G, Sarabon N, Greblo Z, Krizanic V. Effects of feedback-based balance and core resistance training vs. Pilates training on balance and muscle function in older women: a randomized-controlled trial. Arch Gerontol Geriatr 2015; 61(2):117-23. http://doi.org/10.1016/j.archger.2015.05.009.

15. Sienko K, Whitney S, Carender W, Wall III C. The role of sensory augmentation for people with vestibular deficits: real-time balance aid and/or rehabilitation device? J Vestib Res 2017; 27(1):63-76. DOI: 10.3233/VES-170606.

16. Aman JE, Elangovan N, Yeh I, Konczak J. The effectiveness of proprioceptive training for improving motor function: a systematic review. Front Hum Neurosci 2015; 8:1075. http://doi.org/10.3389/fnhum.2014.01075.

17. Ni M, Mooney K, Richards L, Balachandran A, Sun M, Harriell K, et al. Comparative impacts of tai chi, balance training, and a specially-designed yoga program on balance in older fallers. Arch Phys Med Rehabil 2014; 95(9):1620-8. e30. http:// doi.org/10.1016/j.apmr.2014.04.022.

18. Gondim ITGdO, Torres ABdC, Lacerda ATBd, Fernandes DQK, Couto MCd, Pedrosa MAC. Effects of a therapeutic exercises program associated with pompage technique on pain, balance and strength in elderly women with knee osteoarthritis. Fisioterapia em Movimento 2017; 30:11-21. http:// dx.doi.org/10.1590/1980-5918.030.s01.a001.

19. Hewston $P$, Deshpande N. Falls and balance impairments in older adults with type 2 diabetes: thinking beyond diabetic peripheral neuropathy. Can J Diabetes 2016; 40(1):6-9. http://doi.org/10.1016/j.jcjd.2015.08.005.

20. Granacher U, Gollhofer A, Hortobágyi T, Kressig RW, Muehlbauer $T$. The importance of trunk muscle strength for balance, functional performance, and fall prevention in seniors: A systematic review. Sports Med 2013; 43(7):627-41. http://doi.org/10.1007/s40279-013-0041-1.

21. Afridi A, Malik AN, Ali S, Amjad I. Effect of balance training in older adults using Wii Fit plus. J Pak Med Assoc. 2018; 68(3): 480-3.

22. Scaglioni-Solano P, Aragon-Vargas LF. Validity and reliability of the Nintendo Wii Balance Board to assess standing balance and sensory integration in highly functional older adults. Int $J$ Rehabil Res 2014; 37(2):138-43. doi: 10.1097/MRR.000000 0000000046.

23. Clark RA, Mentiplay BF, Pua YH, Bower KJ. Reliability and validity of the Wii Balance Board for assessment of standing balance: $A$ systematic review. Gait Posture 2018; 61:40-54. doi.org/10.1016/j.gaitpost.2017.12.022.

24. Moher D, Liberati A, Tetzlaff J, Altman DG. Preferred reporting items for systematic reviews and meta-analyses: the PRISMA statement. PLoS Med 2009; 6(7):e1000097.

25. Nintendo. Nintendo History. 2020; Available from: http://www.nintendo.co.uk/Corporate/Nintendo-History/Nintendo -History-625945.html.

26. Medicine OCfE-B. Levels of evidence. 2009 [cited 2019 20th Nov ]; Available from: http://www.cebm.net/2009/06/ oxford-centre-evidence-based-medicine-levels-evidence-march-2009/

27. Cho GH, Hwangbo G, Shin HS. The effects of virtual reality-based balance training on balance of the elderly. J Phys Ther Sci 2014; 26(4):615-7. http://doi.org/10.1589/jpts.26.615.

28. Maillot $P$, Perrot A, Hartley A. Effects of interactive physical-activity video-game training on physical and cognitive function in older adults. Psychol Aging 2012; 27(3):589. doi.org/ 


\subsection{7/a0026268.}

29. Rendon AA, Lohman EB, Thorpe D, Johnson EG, Medina E, Bradley $B$. The effect of virtual reality gaming on dynamic balance in older adults. Age Ageing 2012; 41(4):549-52. doi.org/10.1093/ageing/afs053.

30. Franco JR, Jacobs K, Inzerillo C, Kluzik J. The effect of the Nintendo Wii Fit and exercise in improving balance and quality of life in community dwelling elders. Technol Health Care 2012; 20(2):95-115. DOI: 10.3233/THC-2011-0661.

31. Jorgensen MG, Laessoe U, Hendriksen C, Nielsen OB, Aagaard P. Efficacy of Nintendo Wii training on mechanical leg muscle function and postural balance in community-dwelling older adults: a randomized controlled trial. J Gerontol A Biol Sci Med Sci 2013; 68(7):845-52. doi: 10.1093/gerona/gls222. Epub 2012 Oct 31.

32. Toulotte C, Toursel C, Olivier N. Wii Fit ${ }^{\circledR}$ training vs. Adapted Physical Activities: which one is the most appropriate to improve the balance of independent senior subjects? A randomized controlled study. Clin Rehabil 2012; 26(9):827-35. http://doi.org/10.1177/0269215511434996.

33. Fu AS, Gao KL, Tung AK, Tsang WW, Kwan MM. Effectiveness of exergaming training in reducing risk and incidence of falls in frail older adults with a history of falls. Arch Phys Med Rehabil. 2015; 96(12):2096-102. http://doi.org/10.1016/j.apmr. 2015.08.427.

34. Lee $Y$, Choi W, Lee $\mathrm{K}$, Song $\mathrm{C}$, Lee S. Virtual reality training with three-dimensional video games improves postural balance and lower extremity strength in community-dwelling older adults. J Aging Phys Act. 2017; 25(4):621-7. http://doi.org/10. 1123/japa.2015-0271.

35. Morone G, Paolucci T, Luziatelli S, Iosa M, Piermattei C, Zangrando $F$, et al. Wii Fit is effective in women with bone loss condition associated with balance disorders: A randomised controlled trial. Aging Clin Exp Res 2016; 28(6):1187-93. doi.org/10.1007/s40520-016-0578-6.

36. Nicholson VP, McKean M, Lowe J, Fawcett C, Burkett B. Six weeks of unsupervised Nintendo Wii Fit gaming is effective at improving balance in independent older adults. J Aging Phys Act 2015; 23(1):153-8. doi.org/10.1123/JAPA.2013-0148.

37. Merriman NA, Whyatt C, Setti A, Craig C, Newell FN. Successful balance training is associated with improved multisensory function in fall-prone older adults. Comput Hum Behav 2015; 45:192-203. doi.org/10.1016/j.chb.2014.12.017.

38. Whyatt C, Merriman NA, Young WR, Newell FN, Craig C. A Wii bit of fun: A novel platform to deliver effective balance training to older adults. Games Health J 2015; 4(6):423-33. doi.org/10.1089/g4h.2015.0006.

39. Hoffmann TC, Glasziou PP, Boutron I, Milne R, Perera R, Moher $D$, et al. Better reporting of interventions: template for intervention description and replication (TIDieR) checklist and guide. Bmj 2014; 348:g1687. doi.org/10.1136/bmj.g1687.

40. Bonnechère $B$, Jansen $B$, Omelina $L$, Van Sint J. The use of commercial video games in rehabilitation: a systematic review. Int J Rehabil Res 2016; 39(4):277-90. doi.org/10.1097/ MRR.0000000000000190.

41. Goble DJ, Cone BL, Fling BW. Using the Wii Fit as a tool for balance assessment and neurorehabilitation: the first half decade of "Wii-search". J Neuroeng Rehabil 2014; 11:12. doi.org/10.1186/1743-0003-11-12.

42. Kappen DL, Mirza-Babaei P, Nacke LE. Older adults' physical activity and exergames: A systematic review. Int J Hum Comput Interact 2019; 35(2):140-67. doi.org/10.1080/ 10447318.2018. 1441253.

43. Larsen $\mathrm{LH}$, Schou L, Lund HH, Langberg $\mathrm{H}$. The physical effect of exergames in healthy elderly-a systematic review. Games Health J 2013; 2(4):205-12. doi.org/10.1089/g4h.2013.0036.

44. Chang W-D, Chang W-Y, Lee C-L, Feng C-Y. Validity and reliability of Wii Fit balance board for the assessment of balance of healthy young adults and the elderly. J Phys Ther Sci 2013; 25(10):1251-3. doi.org/10.1589/jpts.25.1251.

45. Tripette J, Murakami H, Ryan KR, Ohta Y, Miyachi M. The contribution of Nintendo Wii Fit series in the field of health: A systematic review and meta-analysis. Peer J 2017; 5:e3600. http://doi.org/10.7717/peerj.3600.

46. Pardasaney PK, Slavin MD, Wagenaar RC, Latham NK, Ni P, Jette AM. Conceptual limitations of balance measures for community-dwelling older adults. Phys Ther 2013; 93(10): 1351-68. doi.org/10.2522/ptj.20130028.

47. Chao YY, Scherer YK, Montgomery CA, Wu YW, Lucke KT. Physical and psychosocial effects of Wii Fit exergames use in assisted living residents: A pilot study. Clin Nurs Res 2015; 24(6):589-603. doi.org/10.1177/1054773814562880.

48. Chao Y-Y, Scherer YK, Wu Y-W, Lucke KT, Montgomery CA. The feasibility of an intervention combining self-efficacy theory and Wii Fit exergames in assisted living residents: A pilot study. Geriatr Nurs 2013; 34(5):377-82. http://doi.org/ 10.1016/ j.gerinurse.2013.05.006.

49. di Ruffano LF, Dinnes J, Sitch AJ, Hyde C, Deeks JJ. Test-treatment RCTs are susceptible to bias: a review of the methodological quality of randomized trials that evaluate diagnostic tests. BMC Med Res Methodol 2017; 17(1):35. http://doi.org/10.1186/s12874-016-0287-z.

50. Lin MR, Wolf SL, Hwang HF, Gong SY, Chen CY. A randomised, controlled trial of fall prevention programs and quality of life in older fallers. J Am Geriatr Soc 2007; 55(4):499-506. doi.org/10.1111/j.1532-5415.2007.01146.X.

51. Padala KP, Padala PR, Malloy TR, Geske JA, Dubbert PM, Dennis RA, et al. Wii-fit for improving gait and balance in an assisted living facility: A pilot study. J Aging Res. 2012; 2012. doi.org/10.1155/2012/597573.

52. Ebell MH, Siwek J, Weiss BD, Woolf SH, Susman J, Ewigman B, et al. Strength of recommendation taxonomy (SORT): A patient-centered approach to grading evidence in the medical literature. Am Fam Physician 2004; 69(3):548-56. 